\title{
An algorithm for simulation of the performance of air-cooled heat exchanger applications subject to the influence of complex circuitry
}

\author{
M.C. Kuo ${ }^{\text {a }}$, H.K. Ma ${ }^{\text {a }}$, S.L. Chen ${ }^{\text {a }}$, C.C. Wang ${ }^{\text {b,* }}$ \\ a Department of Mechanical Engineering, National Taiwan University, Taipei 107, Taiwan \\ ${ }^{\mathrm{b}}$ Energy and Resources Laboratories, Industrial Technology Research Institute, D400 ERL/ITRI Buliding 64, 195-6 Section 4, \\ Chung Hsing Rd., Chutung, Hsinchu 310, Taiwan
}

Received 14 September 2004; accepted 21 April 2005

Available online 28 June 2005

\begin{abstract}
The present study develops an index technique to take into account the effect of complex circuitry on the design of fin-and-tube heat exchangers. A 4-index array technique is described in detail that is capable of handling complex circuitry up to second-order level. In addition, a complete modeling of the performance of an evaporator is made. For the performance of evaporations without curved configuration, the proposed model can give good calculations with the experimental data.
\end{abstract}

(C) 2005 Elsevier Ltd. All rights reserved.

Keywords: Circuitry; Fin-and-tube heat exchanger; Evaporator

\section{Introduction}

In the implementation of the air-cooled heat exchangers in refrigeration application, complex circuitry is often encountered as shown in Fig. 1. This is because the process of heat transfer in the tube side involved phase change, giving rise to significant volume changes were refrigerant evaporation or condensation taken place. For the same mass flux, the vapor velocity is considerable higher than that of the liquid phase that eventually leads to an unacceptable friction loss. As a consequence, split or combination of the refrigerant flow inside the tube is a must to provide reasonable pressure drop of the refrigerant flow.

In addition to the concern of frictional loss, there is another benefit of employing multiple-circuitry design of the refrigerant system. As is well known, for effectively improvement of the performance of air-cooled heat exchangers, passive enhancement techniques are

\footnotetext{
${ }^{*}$ Corresponding author. Tel.: +886 35916 294; fax: +88635820250.

E-mail address: ccwang@itri.org.tw (C.C. Wang).
}

often employed. The methods includes: (1) by using enhanced fin surfaces; (2) by increasing total surface area; (3) by increasing the effective mean temperature difference between the air flow and refrigerant flow. Well circuitry design can provide a more uniform temperature distribution and a better heat transfer performance accordingly. Unfortunately, the design of the circuitry usually relied on experience. Rationally based methods are seldom found. There are some discrete simulation methods available in the literature, such as those proposed by Mirth and Ramadhyani [1], and Vardhan and Dhar [2], and Wang and Hihara [3]. However, these methods are applicable only to single-phase fluid flow system at a cross-flow or a counter-cross flow arrangement. For two-phase refrigerant based applications, extension of these methods requires keeping track of the complex circuitry. In the open literature, there was only limited experimental information concerning the circuitry design. For example, Ebisu et al. [4] reported performances of air-cooled heat exchangers with R-410A for three different circuits. They reported that the heat exchanger performances for two and three 


\begin{tabular}{|c|c|c|c|}
\hline \multicolumn{4}{|c|}{ Nomenclature } \\
\hline$A_{\mathrm{f}}$ & surface area of fin $\left(\mathrm{m}^{2}\right)$ & $i_{\mathrm{fg}}$ & latent heat of water vapor $(\mathrm{J} / \mathrm{kg})$ \\
\hline$A_{\mathrm{O}}$ & total surface area $\left(\mathrm{m}^{2}\right)$ & $i_{\mathrm{r}, \mathrm{m}}$ & saturated air enthalpy at the mean refrigerant \\
\hline$A_{\mathrm{p}, \mathrm{i}}$ & inside surface area of tubes $\left(\mathrm{m}^{2}\right)$ & & temperature $(\mathrm{J} / \mathrm{kg})$ \\
\hline$A_{\mathrm{p}, \mathrm{m}}$ & mean heat transfer area of tubes $\left(\mathrm{m}^{2}\right)$ & $i_{\mathrm{s}, \mathrm{p}, \mathrm{i}, \mathrm{m}}$ & saturated air enthalpy at the mean inside tube \\
\hline$A_{\mathrm{p}, \mathrm{o}}$ & outer surface area of tubes $\left(\mathrm{m}^{2}\right)$ & & wall temperature $(\mathrm{J} / \mathrm{kg})$ \\
\hline$b_{\mathrm{p}}^{\prime}$ & $\begin{array}{l}\text { slope of a straight line between the outside } \\
\text { and inside tube wall temperatures }(\mathrm{J} / \mathrm{kg} \mathrm{K})\end{array}$ & $i_{\mathrm{s}, \mathrm{p}, \mathrm{o}, \mathrm{m}}$ & $\begin{array}{l}\text { saturated air enthalpy at the mean outside } \\
\text { tube wall temperature }(\mathrm{J} / \mathrm{kg})\end{array}$ \\
\hline$b_{\mathrm{r}}^{\prime}$ & $\begin{array}{l}\text { slope of the air saturation curved at the mean } \\
\text { coolant temperature }(\mathrm{J} / \mathrm{kg} \mathrm{K})\end{array}$ & $i_{\mathrm{s}, \mathrm{w}, \mathrm{m}}$ & $\begin{array}{l}\text { saturated air enthalpy at the mean water film } \\
\text { temperature of the external surface }(\mathrm{J} / \mathrm{kg})\end{array}$ \\
\hline$b_{\mathrm{w}, \mathrm{m}}^{\prime}$ & slope of the air saturation curve at the mean & $\Delta i$ & mean enthalpy difference $(\mathrm{J} / \mathrm{kg})$ \\
\hline & $\begin{array}{l}\text { water film temperature of the external surface } \\
(\mathrm{J} / \mathrm{kg} \mathrm{K})\end{array}$ & $K_{0}$ & $\begin{array}{l}\text { modified Bessel function solution of the sec- } \\
\text { ond kind, order } 0\end{array}$ \\
\hline$b_{\mathrm{w}, \mathrm{p}}^{\prime}$ & $\begin{array}{l}\text { slope of the air saturation curve at the mean } \\
\text { water film temperature of the primary surface }\end{array}$ & $K_{1}$ & $\begin{array}{l}\text { modified Bessel function solution of the sec- } \\
\text { ond kind, order } 1\end{array}$ \\
\hline & $(\mathrm{J} / \mathrm{kg} \mathrm{K})$ & $k_{\mathrm{f}}$ & thermal conductivity of fin (W/m K) \\
\hline$C_{\mathrm{p}, \mathrm{a}}$ & $\begin{array}{l}\text { moist air specific heat at constant pressure } \\
(\mathrm{J} / \mathrm{kg} \mathrm{K})\end{array}$ & $\begin{array}{l}k_{\mathrm{p}} \\
k_{\mathrm{w}}\end{array}$ & $\begin{array}{l}\text { thermal conductivity of tube }(\mathrm{W} / \mathrm{m} \mathrm{K}) \\
\text { thermal conductivity of water }(\mathrm{W} / \mathrm{m} \mathrm{K})\end{array}$ \\
\hline$D_{\mathrm{c}}$ & tube outside diameter, include collar (m) & $M_{\mathrm{w}}$ & parameter $(1 / \mathrm{m})$ \\
\hline$D_{\mathrm{i}}$ & tube inside diameter $(\mathrm{m})$ & $\dot{m}_{\mathrm{a}}$ & air mass flow rate $(\mathrm{kg} / \mathrm{s})$ \\
\hline$F$ & correction factor & $P_{1}$ & longitudinal tube pitch (m) \\
\hline$F_{\mathrm{p}}$ & fin pitch $(\mathrm{m})$ & $P_{\mathrm{t}}$ & transverse tube pitch $(\mathrm{m})$ \\
\hline$G$ & mass flux of refrigerant flow $\left(\mathrm{kg} / \mathrm{m}^{2} \mathrm{~s}\right)$ & $\dot{Q}_{\text {wet }}$ & heat transfer rate $(\mathrm{W})$ \\
\hline$h_{\mathrm{c}, \mathrm{o}}$ & sensible heat transfer coefficient for wet coils & $T$ & temperature $(\mathrm{K})$ \\
\hline & $\left(\mathrm{W} / \mathrm{m}^{2} \mathrm{~K}\right)$ & $T_{\mathrm{a}, \mathrm{i}}$ & inlet temperature of air (K) \\
\hline$h_{\mathrm{i}}$ & inside heat transfer coefficient $\left(\mathrm{W} / \mathrm{m}^{2} \mathrm{~K}\right)$ & $T_{\mathrm{a}, \mathrm{o}}$ & outlet temperature of air $(\mathrm{K})$ \\
\hline$h_{\mathrm{o}, \mathrm{w}}$ & $\begin{array}{l}\text { total heat transfer coefficient for wet external } \\
\text { fin }\left(\mathrm{W} / \mathrm{m}^{2} \mathrm{~K}\right)\end{array}$ & $\begin{array}{l}T_{\mathrm{w}, \mathrm{m}} \\
T_{\mathrm{p}, \mathrm{i}, \mathrm{m}}\end{array}$ & $\begin{array}{l}\text { mean temperature of the water film }(\mathrm{K}) \\
\text { mean temperature of the inner tube wall }(\mathrm{K})\end{array}$ \\
\hline$I, J$ & tube index & $T_{\mathrm{p}, \mathrm{o}, \mathrm{m}}$ & mean temperature of the outer tube wall $(\mathrm{K})$ \\
\hline$I_{0}$ & modified Bessel function solution of the first & $T_{\mathrm{r}, \mathrm{m}}$ & mean temperature of refrigerant coolant $(\mathrm{K})$ \\
\hline & kind, order 0 & $U_{\mathrm{o}, \mathrm{w}}$ & overall heat transfer coefficient $\left(\mathrm{kg} / \mathrm{m}^{2} \mathrm{~s}\right)$ \\
\hline$I_{1}$ & modified Bessel function solution of the first & $x_{\mathrm{p}}$ & thickness of tube wall (m) \\
\hline & kind, order 1 & $y_{\mathrm{w}}$ & thickness of the condensate water film (m) \\
\hline & air enthalpy $(\mathrm{J} / \mathrm{kg})$ & $\delta_{\mathrm{f}}$ & fin thickness (m) \\
\hline & inlet air enthalpy $(\mathrm{J} / \mathrm{kg})$ & $\eta_{\mathrm{f} \text {,wet }}$ & wet fin efficiency \\
\hline$i_{\mathrm{a}, \text { out }}$ & outlet air enthalpy $(\mathrm{J} / \mathrm{kg})$ & & \\
\hline
\end{tabular}

circuits surpassed that of 1-circuit design by $17 \%$ and $19 \%$, respectively. Wang et al. [5] investigated the effect of circuitry on the performance of air-cooled condensers. They had provided in-depth experimental information related to the effect of circuitry in the air-cooled condensers. Their results showed that counter-cross flow gave better performance than other arrangements for 1circuit arrangements. However, the reversed heat conduction from the inlet portion to the exit portion may offset the benefit of counter-cross arrangement. Wang et al. [6] performed experiments to examine the pressure drop of the refrigerant flow in a counter, parallel, and $z$-shape circuitry in evaporators. Their results showed that the parallel-cross flow circuit gives the largest pressure drop than other arrangements and generally the refrigerant-side pressure drops increase with frontal velocities. However, for $G=200 \mathrm{~kg} / \mathrm{m}^{2} \mathrm{~s}$, the pressure drops decrease with increase of frontal velocity. The unusual characteristics are likely related to the flow pattern transition subjected to heat addition.

In contrast to experimental studies of the influence of the circuitry, theoretical study concerning the influence of the circuitry is even limited. Possible reason for this limitation is the lacks of effective algorithm to keep track of the refrigerant flow during the simulation. Domanski [7] developed a HPSIM model that is able to handle some limited circuitry design such as counter-current arrangement. The only algorithm available in the open literature was developed by Ellision et al. [8]. Their index is a tube-by-tube based technique and is limited to splitting or combining from or to two tubes. As seen, Ellision et al.'s effort is the only general algorithm to 
index the complex circuitry. In that regard, it is the purpose of this study to present an alternative and simple algorithm that is capable of handling multiple splitting or combing of the tubes to record the index of the complex circuitry and to examine its applicability.

\section{Proposed index technique}

As given in the introduction, the complex circuitry involves splitting and combining of the refrigerant flow. For easier tacking of the refrigerant flow, the refrigerant flow just after the expansion device is denoted as the main flow. Notice that the main flow before entering the heat exchangers can be of single or multiple circuits. The flow is regarded as the first level flow if splitting is encountered. If there is further splitting in the first level, the flow is considered as the second level. This study is limited to second level in describing the proposed algorithm. However, extending to the third or higher level is very straightforward. As a consequence, an array with indices of $n, i, j$, and $m$ is used and termed as $[n, i, j, m]$. The array is capable

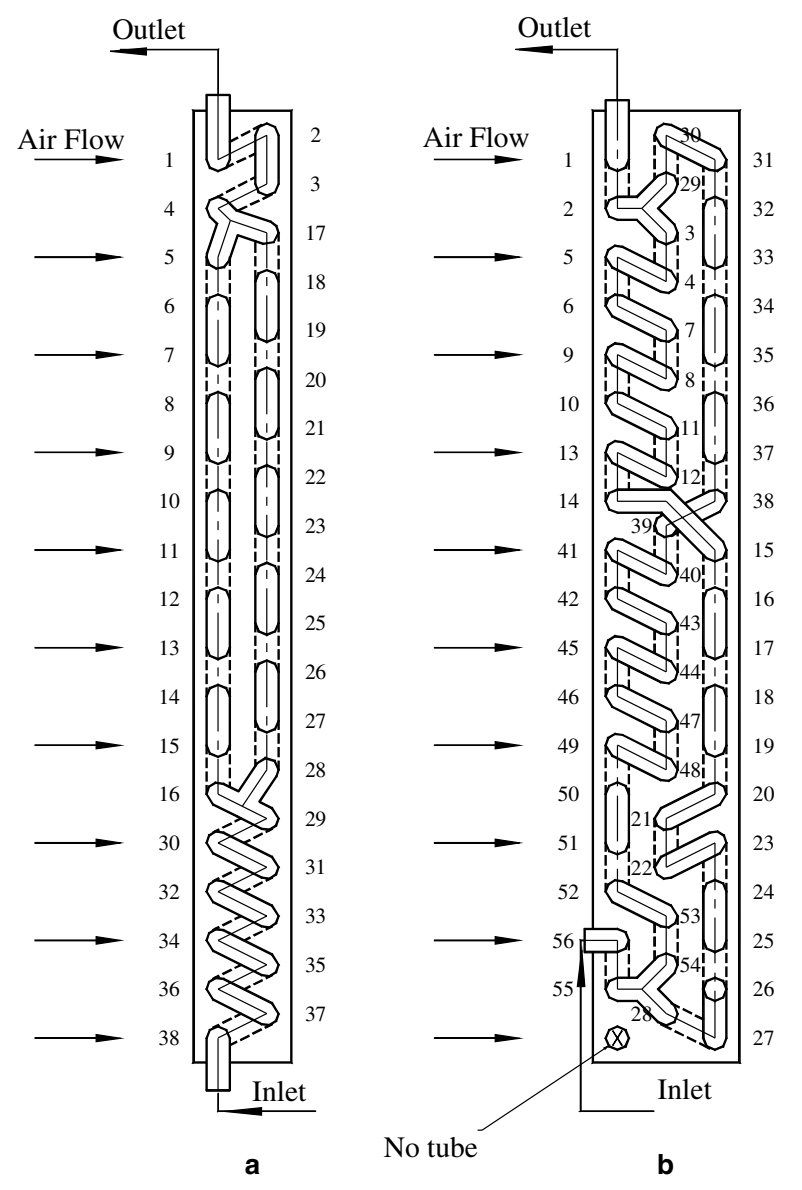

Fig. 1. Schematic of a refrigerant heat exchanger. of describing the index system of the refrigerant flow. The indices of $n, i, j, m$ are as follows:

$n$ : denotes the number of main flows before entering the heat exchangers.

$i$ : refers to as the number of the first level circuitry, and the associated values can be 0,1 , or 2 . For example, the value of 0 indicates that it is at the position without splitting or is at the location where circuitry are combining at the end. The value of 1 indicates this part is inherited from the first level. Notice that the value can be easily extended to higher value $(>2)$ if splitting from or re-combining to for more than two tubes. The algorithm by Ellision et al. [8] is strictly limited to two tubes.

$j$ : refers to as the number of the second level circuitry, and the associated values can be 0,1 , or 2. For example, the value of 0 indicates that it is at the position without splitting or is at the location where circuitry is combining at the end. The value of 1 indicates this part is inherited from the first level. Notice that the value can be easily extended to higher value $(>2)$ if splitting from or re-combining to for more than two tubes.

$m$ : denotes as the splitting/combining index, the corresponding value is from 0 to 6 .

Relevant meaning is as follows:

0: normal node in the circuitry.

1: inlet of the heat exchanger.

2: splitting node.

3: after splitting.

4: before combining.

5: combining node.

6: outlet of the heat exchanger.

For easier understanding of the proposed index technique, a couple of examples as schematically shown in Fig. 2 is adopted for demonstration. For Fig. 2(A), there is only one main flow entering the heat exchanger, therefore the $n$-index is always 1 for every node. As the refrigerant flows further downstream, if there is no splitting, the second index of $i$ is 0 indicating that the flow is in the main flow. As the main flow meets the splitting point at $[1,0,0,2]$ where the third index $j$ is also 0 showing that this node is still in the main flow but the last index $m$ is 2 showing that this node is a splitting node. Analogously, the left branch of the circuitry all begins with an $i$-index of 1 because this part belongs to the first circuitry after splitting whereas the right branch possesses an $i$-index of 2 revealing this part belongs to the second circuitry of the first level. Similarly, additional splitting node is encountered at node $[1,1,0,2]$ as the refrigerant flows further downstream, thus the third index of the left 

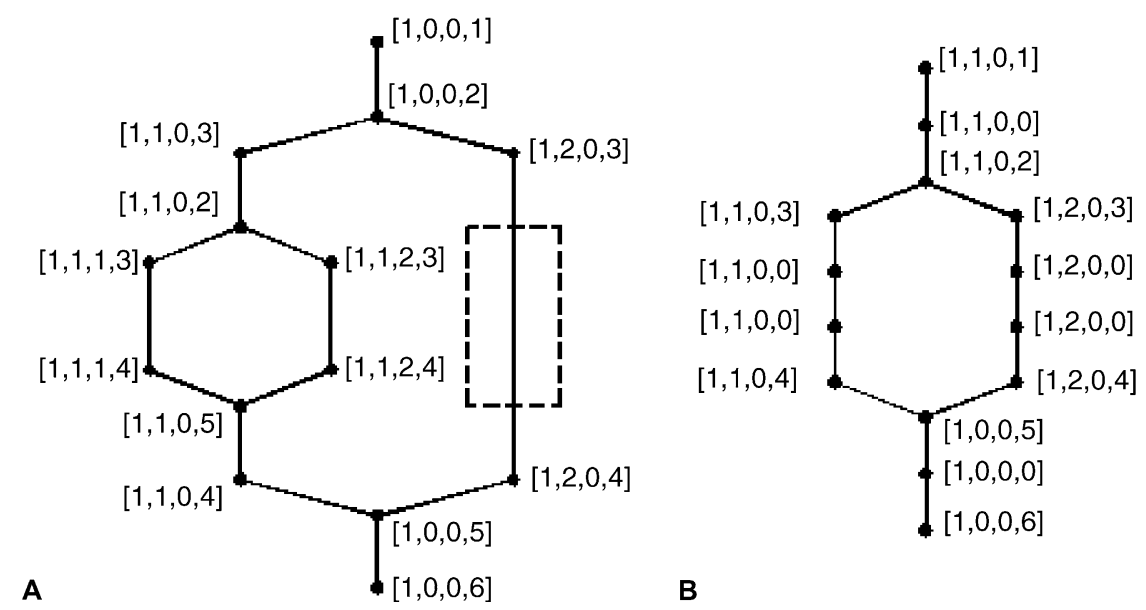

Fig. 2. Examples of the proposed index techniques.

branch after node $[1,1,0,2]$ are 1 whereas the $j$-index of right branch is 2 . Meanwhile, the third index of node $[1,2,0,3]$ and $[1,2,0,4]$ are all 0 because there is no additional splitting. The $j$-index and $m$-index of node $[1,1,0,5]$ is 0 and 5 accordingly because the flow is recombining at this node. The $m$-index of node $[1,1,0,4]$ is 4 because this is a node before combining. For Fig. 2(B), similar algorithm applies and the related node array is given in the Figure. Note that the present algorithm can subdivide the heat exchanger into smaller element as the node $[1,0,0,0]$ of Fig. 2(B) for more accurate calculations. The algorithm by Ellision et al. [8] was unable to perform this duty. Advances of the proposed index technique are summarized as follows:

(1) The circuitry arrangement can be extended to both sides of the tube (in both active and inactive side, Ellision et al.'s algorithm is applicable to active side only).

(2) Applicable to multiple ( $>2)$ splitting and combination.

(3) The proposed indexed array needs only very small storage to keep track of all the variations.

(4) No restrictions to the fluid flow directions for circuitry arrangements, the refrigerant and air flow arrangement can be of counter-cross or counterparallel arrangement in any instant.

(5) The proposed index technique can handle the momentum balance after splitting and re-combination. As a consequence, mal-distributions within multiple circuitry are therefore predictable.

To solve the refrigerant flow distribution subject to the influence of circuitry, a step-by-step procedure is needed to balance the mass and pressure drop in the circuitry. The following are examples showing this step-bystep procedure for the second level circuitry of Fig. 2(A):
1. For an initial assumption, the mass flow in each circuit is obtained by dividing the total mass flow rate to the number of the circuits.

2. Calculation of the heat transfer rate and the pressure drop from node $[1,0,0,1]$ to subsequent section (to node $[1,0,0,2]$ ).

3 . At the splitting node of $[1,0,0,2]$, the mass flow rate is presumed to be equal. The initial value is the mass flow rate divided by the number of circuits. Calculations are then made from steps (4) to (12).

4. Solve the first level result for node after $[1,1,0,3]$. If the second level splitting point $[1,1,0,3]$ is encountered, perform the procedures of (5)-(9); otherwise, go to step (10).

5. Equally divide the refrigerant flow rate to serve as the initial value of the entering mass flow rate of $[1,1,1,3]$ and $[1,1,2,3]$.

6. Perform calculations from $[1,1,1,3]$ to $[1,1,1,4]$.

7. Perform calculations from $[1,1,2,3]$ to $[1,1,2,4]$.

8. Compare the outlet pressure at $[1,1,1,4]$ and $[1,1,2,4]$. If it is identical, go to step (9); if not, adjust the refrigerant mass flow rate distribution at $[1,1,1,3]$ and $[1,1,2,3]$ and repeat procedure from (6).

9. Obtain the mean enthalpy of the refrigerant at $[1,1,1,4]$ and $[1,1,2,4]$ to serve as the initial refrigerant enthalpy of $[1,1,0,5]$. The total mass flow rate at the combining node of $[1,1,0,5]$ is obtained from the summation of $[1,1,1,4]$ and $[1,1,2,4]$.

10. Perform the calculation to $[1,1,0,4]$.

11. As shown in steps (4)-(10), perform the calculations from $[1,2,0,3]$ to $[1,2,0,4]$.

12. Compare the outlet pressure at $[1,1,0,4]$ and $[1,1,2,4]$. If identical, go to step (13); if not, adjust the refrigerant flow distribution at $[1,1,0,3]$ and $[1,1,2,3]$ and repeat the procedures from step (4). 
13. Obtain the mean enthalpy of the refrigerant at $[1,1,0,4]$ and $[1,1,2,4]$ to serve as the initial enthalpy of $[1,0,0,5]$. The total mass flow rate at the combining node of $[1,0,0,5]$ is the summation of $[1,1,0,4]$ and $[1,1,2,4]$.

14. Perform the calculation to $[1,0,0,6]$.

15. Perform the calculation for the $n$-branch $(n=2)$, return to step (2) to continue the calculation procedures from (2) to (14).

16. Perform the calculation until $n$ is equal to the total number of main flow. Then make a comparison of the outlet pressures for all the main flow at the outlet, i.e. $[1,0,0,6],[2,0,0,6] \ldots$ etc. If it is not identical, adjust the mass flow rate distribution of the branch of the main flow rate then go to step (2) for repeating calculation.

17. Calculations are performed until convergence.

Detailed flow chart of the circuitry design is shown in Fig. 3.

\section{Solution algorithm of the heat exchanger model}

In additional to the proposed index technique, and the related balance of the refrigerant-side distribution, some additional heat transfer, and frictional equations are needed to perform the calculation. The present model focused on the performance of the evaporator. However, change the simulation algorithm to the condenser should be very easy. For the heat transfer in the airside of the evaporator involves both heat and mass transfer. Thus, the enthalpy-based method proposed by Threlkeld [9] is adopted. The heat transfer rate in the evaporator is calculated as

$\dot{Q}_{\text {wet }}=\dot{m}_{\mathrm{a}}\left(i_{\mathrm{ai}}-i_{\mathrm{ao}}\right)$

where $i_{\mathrm{ai}}$ and $i_{\mathrm{ao}}$ are the inlet and outlet enthalpy of the air flow. The rating equation of the dehumidifying heat exchanger, according to Threlkeld [9], is

$\dot{Q}_{\text {wet }}=U_{\text {ow }} A_{\mathrm{o}} F \Delta i_{\mathrm{m}}$

where $U_{\text {ow }}$ is the enthalpy-based overall heat transfer coefficient, $F$ is the correction factor and $\Delta i_{\mathrm{m}}$ is the log mean enthalpy difference. For counter flow arrangement, $\Delta i_{\mathrm{m}}$ is given as follows $[10,11]$ :

$\Delta i_{\mathrm{m}}=\frac{\left(i_{\mathrm{ai}}-i_{\mathrm{ro}}\right)-\left(i_{\mathrm{ao}}-i_{\mathrm{ri}}\right)}{\ln \left(\frac{i_{\mathrm{ai}}-i_{\mathrm{ro}}}{i_{\mathrm{ao}}-i_{\mathrm{ri}}}\right)}$

The enthalpy-based overall heat transfer coefficient $U_{\mathrm{o}, \mathrm{w}}$ in Eq. (2) is evaluated as [12]

$U_{\mathrm{o}, \mathrm{w}}=\left[\frac{b_{\mathrm{r}}^{\prime} A_{\mathrm{o}}}{h_{\mathrm{i}} A_{\mathrm{p}, \mathrm{i}}}+\frac{b_{\mathrm{p}}^{\prime} x_{\mathrm{p}} A_{\mathrm{o}}}{k_{\mathrm{p}} A_{\mathrm{p}, \mathrm{m}}}+\frac{1}{h_{\mathrm{o}, \mathrm{w}}\left(\frac{A_{\mathrm{p}, \mathrm{o}}}{b_{\mathrm{w}, \mathrm{p}}^{\prime} A_{\mathrm{o}}}+\frac{A_{\mathrm{f}} \eta_{\mathrm{f}, \mathrm{wet}}}{b_{\mathrm{w}, \mathrm{m}} A_{\mathrm{o}}}\right)}\right]^{-1}$ where

$h_{\mathrm{o}, \mathrm{w}}=\frac{1}{\frac{C_{\mathrm{p}, \mathrm{a}}}{b_{\mathrm{w}, \mathrm{m}}^{\prime} h_{\mathrm{c}, \mathrm{o}}}+\frac{y_{\mathrm{w}}}{k_{\mathrm{w}}}}$

Note that $y_{\mathrm{w}}$ in Eq. (5) is the thickness of the condensate water film. A constant condensate film thickness of 0.005 in., was proposed by Myers [11]. In practice, $\frac{y_{\mathrm{w}}}{k_{\mathrm{w}}}$ accounts only $0.5-5 \%$ comparing to $\frac{C_{\mathrm{p}, \mathrm{a}}}{b_{\mathrm{w}, \mathrm{m}} h_{\mathrm{c}, \mathrm{o}}}$ and is often neglected by previous investigators. As a result, this term is not included in the final analysis. The wet fin efficiency in Eq. (4) is calculated as

$$
\begin{aligned}
\eta_{\mathrm{wet}, \mathrm{f}}= & \frac{2 r_{\mathrm{c}}}{M_{\mathrm{w}}\left(r_{\mathrm{eq}}^{2}-r_{\mathrm{c}}^{2}\right)} \\
& \times\left[\frac{K_{1}\left(M_{\mathrm{w}} r_{\mathrm{c}}\right) I_{1}\left(M_{\mathrm{w}} r_{\mathrm{eq}}\right)-K_{1}\left(M_{\mathrm{w}} r_{\mathrm{eq}}\right) I_{1}\left(M_{\mathrm{w}} r_{\mathrm{c}}\right)}{K_{1}\left(M_{\mathrm{w}} r_{\mathrm{eq}}\right) I_{0}\left(M_{\mathrm{w}} r_{\mathrm{c}}\right)+K_{0}\left(M_{\mathrm{w}} r_{\mathrm{c}}\right) I_{1}\left(M_{\mathrm{w}} r_{\mathrm{eq}}\right)}\right]
\end{aligned}
$$

where

$M_{\mathrm{w}}=\sqrt{\frac{2 h_{\mathrm{o}, \mathrm{w}}}{k_{\mathrm{f}} \delta_{\mathrm{f}}}}=\sqrt{\frac{2 h_{\mathrm{c}, \mathrm{o}}}{k_{\mathrm{f}} \delta_{\mathrm{f}}}} \times \sqrt{\frac{b_{\mathrm{w}, \mathrm{m}}^{\prime}}{C_{\mathrm{p}, \mathrm{a}}}}$

$r_{\mathrm{c}}$ is radius including collar and $r_{\mathrm{eq}}$ is the equivalent radius for circular fin. For the present plate fin geometry, Threlkeld [9] recommended the following approximation:

$r_{\mathrm{eq}}=\sqrt{\frac{p_{\mathrm{t}} \times p_{1}}{\pi}}$

Notice that the evaluation of wet fin efficiency is quite controversy in the open literature. Interested readers should refer to a recent article by Lin et al. [13] for further discussion. The present study adopts the enthalpybased wet fin efficiency. Also shown in Eq. (4), there are four quantities $\left(b_{\mathrm{w}, \mathrm{m}}^{\prime}, b_{\mathrm{w}, \mathrm{p}}^{\prime}, b_{\mathrm{p}}^{\prime}\right.$, and $\left.b_{\mathrm{r}}^{\prime}\right)$ involving enthalpy-temperature ratios that must be evaluated. The quantities of $b_{\mathrm{p}}^{\prime}$, and $b_{\mathrm{r}}^{\prime}$ can be calculated as

$b_{\mathrm{r}}^{\prime}=\frac{i_{\mathrm{s}, \mathrm{p}, \mathrm{i}, \mathrm{m}}-i_{\mathrm{r}, \mathrm{m}}}{T_{\mathrm{p}, \mathrm{i}, \mathrm{m}}-T_{\mathrm{r}, \mathrm{m}}}$

$b_{\mathrm{p}}^{\prime}=\frac{i_{\mathrm{s}, \mathrm{p}, \mathrm{o}, \mathrm{m}}-i_{\mathrm{s}, \mathrm{p}, \mathrm{i}, \mathrm{m}}}{T_{\mathrm{p}, \mathrm{o}, \mathrm{m}}-T_{\mathrm{p}, \mathrm{i}, \mathrm{m}}}$

The values of $b_{\mathrm{w}, \mathrm{p}}^{\prime}$ and $b_{\mathrm{w}, \mathrm{m}}^{\prime}$ are the slope of saturated enthalpy curve evaluated at the outer mean water film temperature that is at the base surface and at the fin surface. Without loss of generality, $b_{\mathrm{w}, \mathrm{p}}^{\prime}$ can be approximated by the slope of saturated enthalpy curve evaluated at the base surface temperature [12]. Unfortunately, there is no explicit way to evaluate $b_{\mathrm{w}, \mathrm{m}}^{\prime}$, and it must be determined by trial and error procedures. The evaluation procedure is as follows:

(1) Assume a value of $T_{\mathrm{w}, \mathrm{m}}$ and determine its corresponding value of $b_{\mathrm{w}, \mathrm{m}}^{\prime}$. 


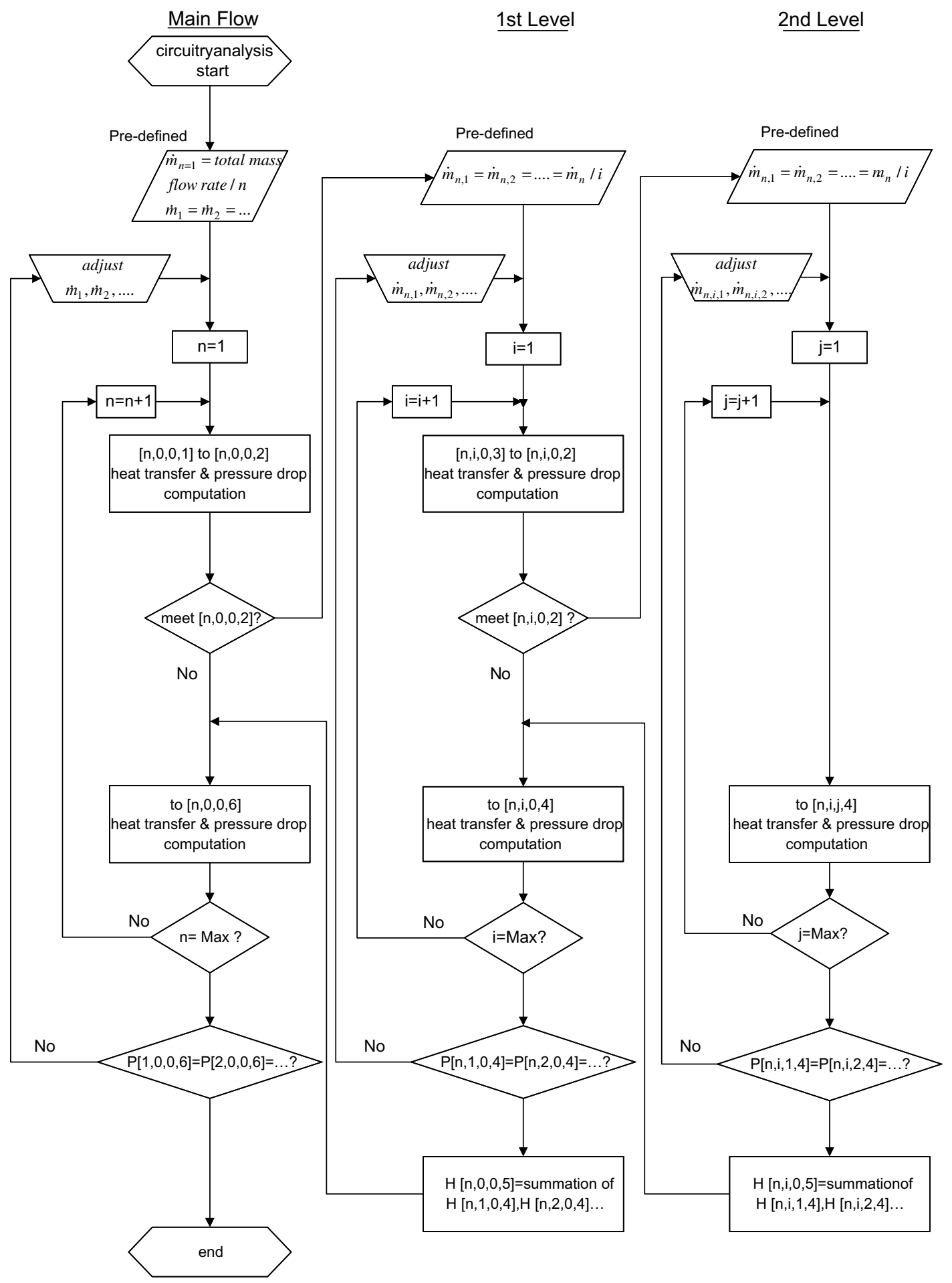

Fig. 3. Circuitry flow chart of the proposed index techniques.

(2) Obtain the overall heat transfer coefficient, $h_{\mathrm{o}, \mathrm{w}}$, from Eq. (5).

(3) Evaluate the wet fin efficiency from Eq. (6).

(4) Calculate the enthalpy-based overall heat transfer coefficient $U_{\mathrm{o}, \mathrm{w}}$ from Eq. (4).

(5) Calculate the $i_{\mathrm{s}, \mathrm{w}, \mathrm{m}}$ using the following equation;

$$
\begin{gathered}
i_{\mathrm{s}, \mathrm{w}, \mathrm{m}}=i-\frac{C_{\mathrm{p}, \mathrm{a}} h_{\mathrm{o}, \mathrm{w}} \eta_{\mathrm{wet}, \mathrm{f}}}{b_{\mathrm{w}, \mathrm{m}}^{\prime} h_{\mathrm{c}, \mathrm{o}}}\left(1-U_{\mathrm{o}, \mathrm{w}} A_{\mathrm{o}}\left[\frac{b_{\mathrm{r}}^{\prime}}{h_{\mathrm{i}} A_{\mathrm{p}, \mathrm{i}}}+\frac{x_{\mathrm{p}} b_{\mathrm{p}}^{\prime}}{k_{\mathrm{p}} A_{\mathrm{p}, \mathrm{m}}}\right]\right) \\
\left(i-i_{\mathrm{r}, \mathrm{m}}\right)
\end{gathered}
$$

(6) Determine $T_{\mathrm{w}, \mathrm{m}}$ at $i_{\mathrm{s}, \mathrm{w}, \mathrm{m}}$. If it is not the same with the assumed value, assume a new value and repeat the procedure. 
The empirical correlations for various fin patterns of the sensible heat transfer coefficients $h_{\mathrm{o}}$ in wet conditions can be summarized from a recent article by Wang et al. [14]. Calculation of the two-phase evaporation heat transfer coefficient is based on the Kandlikar correlation [15].

\section{Simulation procedures of the performance of the evaporator}

For more accurate evaluation of the performance of the evaporator, the heat exchanger can be sub-divided into small elements such as shown in Fig. 4. Calculation procedures of the performance of the small element are illustrated as follows:

(1) Given the inlet conditions of $T_{\mathrm{r}, \mathrm{i}}, T_{\mathrm{a}, \mathrm{i}}$ and $\mathrm{d} A_{\mathrm{o}}$

(2) Calculate the wet fin efficiency from Eq. (6).

(3) Assume the heat transfer rate of this element $\mathrm{d} Q$.

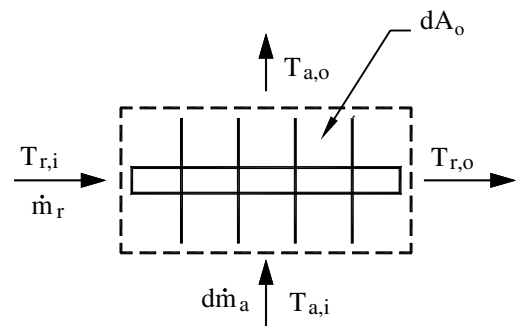

Fig. 4. Schematic of the small element of the modeled heat exchanger.
(4) Obtain the outlet enthalpy of this element $i_{\mathrm{a}, \mathrm{o}}$.

(5) Calculate the in-tube wall temperature $T_{\mathrm{p}, \mathrm{i}}$. Then $b_{\mathrm{r}}^{\prime}$ can be obtained from Eq. (10).

(6) Calculate the in-tube wall temperature $T_{\mathrm{p}, \mathrm{o}}$. Then $b_{\mathrm{p}}^{\prime}$ can be obtained from Eq. (9).

(7) Calculate the film temperature $T_{\mathrm{f}}$ and use the aforementioned procedures to obtain $b_{\mathrm{w}, \mathrm{m}}^{\prime}$.

(8) Obtain the overall heat transfer coefficient from Eq. (4).

(9) Calculate the outlet enthalpy $i_{\mathrm{a}, \mathrm{o}}$ from the rate equation (Eq. (2)).

(10) If calculated result of $i_{\mathrm{a}, \mathrm{o}}$ does not equal to its original assumption from (3), then adjust the initially guessed value, repeat the procedures from (3) to (10).

(11) Continue to the next section.

(12) Repeat (3)-(11).

\section{Results and discussion}

To verify the capability of the proposed modeling, calculated results were compared with the test results from five evaporators in the environmental chamber of Taiwan Hitachi Co. Detailed description of the test evaporators are tabulated in Table 1. Refrigerant R-22 is the working fluid used for the simulation of the evaporator. The performance tests were conducted in an environmental chamber that can provide temperature and humidity control. The schematic of the environmental

Table 1

Configurations of the simulated heat exchanger and the simulated results

\begin{tabular}{|c|c|c|c|c|c|c|}
\hline & Item & Case 1 & Case 2 & Case 3 & Case 4 & Case 5 \\
\hline \multirow[t]{16}{*}{ Size and operation conditions } & Width $\left(10^{-3} \mathrm{~m}\right)$ & 314 & 314 & 478 & 355 & 375 \\
\hline & Height $\left(10^{-3} \mathrm{~m}\right)$ & 325 & 325 & 325 & 325 & 325 \\
\hline & No. of series & 2 & 2 & 2 & 3 & 4 \\
\hline & No. of section & 13 & 13 & 14 & 15 & 16 \\
\hline & Series spacing $\left(10^{-3} \mathrm{~m}\right)$ & 21.65 & 21.65 & 21.65 & 21.65 & 21.65 \\
\hline & Section spacing $\left(10^{-3} \mathrm{~m}\right)$ & 25 & 25 & 25 & 25 & 25 \\
\hline & Pipe outer diameter $\left(10^{-3} \mathrm{~m}\right)$ & 10.05 & 10.05 & 10.05 & 10.05 & 10.05 \\
\hline & Pipe thickness $\left(10^{-3} \mathrm{~m}\right)$ & 0.455 & 0.455 & 0.455 & 0.455 & 0.455 \\
\hline & Fin pitch $\left(10^{-3} \mathrm{~m}\right)$ & 1.6 & 1.5 & 1.5 & 2.0 & 1.8 \\
\hline & Fin thickness $\left(10^{-3} \mathrm{~m}\right)$ & 0.11 & 0.11 & 0.11 & 0.11 & 0.11 \\
\hline & Total air flow rate (CMM) & 6.42 & 6.85 & 8.25 & 9.32 & 13.60 \\
\hline & Coolant flux $(\mathrm{kg} / \mathrm{h})$ & 54.647 & 64.831 & 77.163 & 94.361 & 142.856 \\
\hline & Temperature before expansion $\left({ }^{\circ} \mathrm{C}\right)$ & 43.1 & 42.5 & 40.1 & 47.9 & 43.2 \\
\hline & Inlet pressure $(\mathrm{kPa})$ & 650.2 & 611.0 & 630.6 & 660.0 & 660.0 \\
\hline & Fin area $\left(\mathrm{m}^{2}\right)$ & 4.71 & 5.03 & 8.24 & 7.38 & 12.32 \\
\hline & Average air velocity $(\mathrm{m} / \mathrm{s})$ & 1.05 & 1.12 & 0.82 & 1.17 & 1.51 \\
\hline \multirow[t]{2}{*}{ Test results } & Outlet temperature $\left({ }^{\circ} \mathrm{C}\right)$ & 9.1 & 8.2 & 9.2 & 10.3 & 14.2 \\
\hline & (A) Capacity $(\mathrm{kJ} / \mathrm{h})$ & 8490.4 & 10127.9 & 12346.4 & 14140.9 & 22464.2 \\
\hline \multirow[t]{4}{*}{ Computation } & Outlet temperatur $\left({ }^{\circ} \mathrm{C}\right)$ & 13.0 & 11.5 & 14.7 & 7.3 & 17.0 \\
\hline & Outlet pressure $(\mathrm{kPa})$ & 635.3 & 594.1 & 605.7 & 627.5 & 581.5 \\
\hline & (B) Capacity $(\mathrm{kJ} / \mathrm{h})$ & 8647.3 & 10288.8 & 12605.7 & 12806.3 & 23127.8 \\
\hline & Unit area capacity & 1835.9 & 2045.5 & 1529.8 & 1735.3 & 1877.3 \\
\hline Error & $(\mathrm{B}-\mathrm{A}) / \mathrm{A} \times 100 \%$ & $1.848 \%$ & $1.589 \%$ & $2.100 \%$ & $-9.438 \%$ & $2.954 \%$ \\
\hline
\end{tabular}




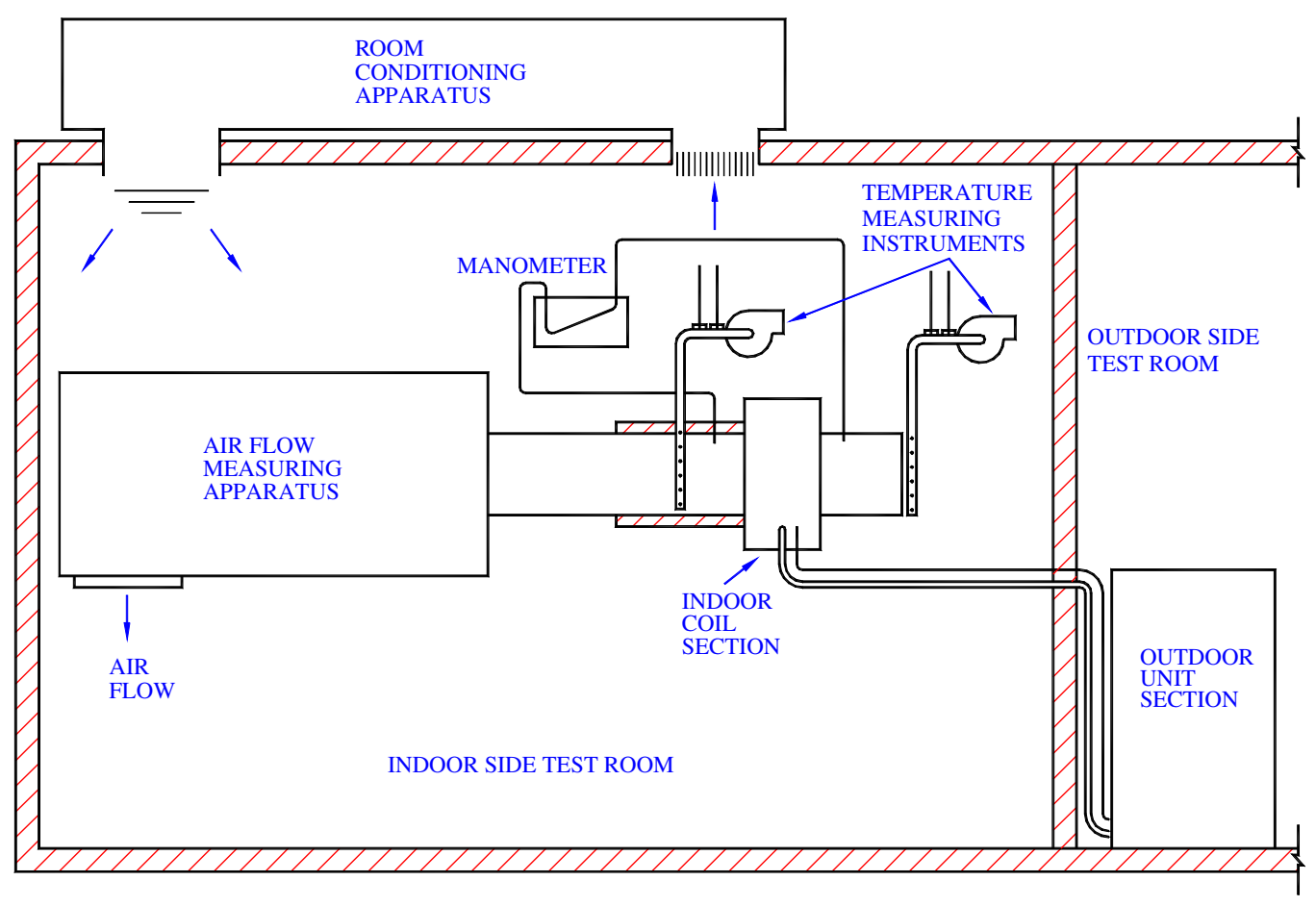

Fig. 5. Schematic of the test apparatus.

chamber is shown in Fig. 5. Notice that the major measuring apparatus in the environmental chamber are regularly calibrated. The test apparatus is based on the air-enthalpy method proposed by ANSI/ASHRAE standard [16]. Cooling capacity was measured from the enthalpy difference of the airflow rate in the indoor coil. Maximum uncertainty of the measured cooling capacity is less than $2 \%$. The airflow measuring apparatus is constructed based on ASHRAE 41.2 standard [17]. Refrigerant temperatures were measured by T-type thermocouples mounted on the surface of the copper tubes and are well-insulated from the ambient. Two pressure transducers were installed at the entrance and exit of the compressor to measure the discharge and suction pressure. The corresponding measurement uncertainties of temperatures and pressure are $0.1{ }^{\circ} \mathrm{C}$ and $1 \mathrm{kPa}$, respectively. Performance tests were conducted at standard condition:

$$
\begin{aligned}
& \text { Indoor : } 27 \pm 0.1{ }^{\circ} \mathrm{C} \mathrm{DB}, 19.5 \pm 0.1{ }^{\circ} \mathrm{C} \mathrm{WB} \\
& \text { Outdoor: } 35 \pm 0.1{ }^{\circ} \mathrm{C} \mathrm{DB}, 24 \pm 0.1{ }^{\circ} \mathrm{C} \text { WB }
\end{aligned}
$$

Comparisons between the experimental results and the calculated results are tabulated in Table 1 and in Fig. 6. As shown in the table and in Fig. 6, for cases 1-3 and case 5, the predictive cooling capacity of the proposed model against the test results is within $3 \%$. This validates the predicted ability of the present model and the related index technique. However, one can see an under-prediction of $9.4 \%$ of the cooling capacity is seen for case 4 . This is because of the curved configura-

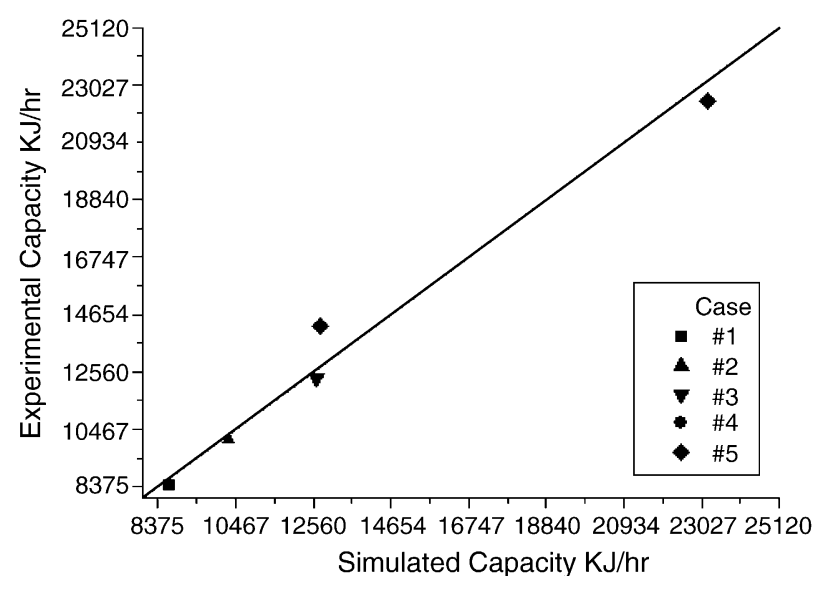

Fig. 6. Comparison of the simulated results with the experimental data.

tion of the evaporator in case 4 whereas the rest are of straight configuration. In this regard, the related influence of airflow mal-distribution for case 4 is more pronounced.

\section{Conclusion}

The present study develops an index technique to take into account the effect of complex circuitry and a relevant model to simulate the performance of the evaporator. The proposed 4-index array technique is described in the present study that is capable of handling 
complex circuitry up to the second-order level. A detailed example is given to describe the proposed technique. The present index technique is capable of handling splitting or combining from more than two tubes and can have further subdivisions along the refrigerant pass for more accurate calculation. In addition, a complete modeling of the performance of an evaporator is made. For the performance of evaporations without curved configuration, the proposed model gives sufficiently accurate calculations with the experimental data.

\section{Acknowledgements}

This research was funded by the National Science Council (NSC 91-2623-7-002-020-ET) and Taiwan Hitachi Co. (1999-2001). Dr. C.C. Wang wishes to thank the Energy R\&D foundation funding from the Energy Bureau of the Ministry of Economic Affairs, Taiwan, for supporting this work.

\section{References}

[1] D.R. Mirth, S. Ramadhyani, Prediction of cooling coil performance under condensing conditions, Int. J. Heat Fluid Flow 14 (1993) 391-399.

[2] A. Vardhan, P.L. Dhar, New procedure for performance prediction of air conditioning coils source, Int. J. Refrig. 21 (1998) 7783.

[3] J. Wang, E. Higara, Prediction of air coil performance under partially wet and totally wet cooling conditions, using equivalent dry-bulb temperature method, Int. J. Refrig. 26 (2003) 293-301.
[4] T. Ebisu, K. Yoshida, K. Torikoshi, Air-cooled heat exchanger performance for R-410A, in: Proceedings of 1996 Int. Refrigerant Conf., Purdue, USA, 1996, pp. 139-144.

[5] C.C. Wang, J.Y. Jang, C.C. Lai, Y.J. Chang, Effect of circuit arrangement on the performance of air-cooled condensers, Int. J. Refrig. 22 (1999) 275-282.

[6] C.C. Wang, M.S. Liu, J.S. Leu, Influence of circuitry arrangement on the pressure drops of two-row finned tube evaporators, ASME J. Energy Resour. Technol. 123 (2001) 100-103.

[7] P.A. Domanski, Simulation of an evaporator with nonuniform one-dimensional air distribution, ASHRAE Trans. 98 (1) (1992) 793-802.

[8] R.D. Ellison, F.A. Creswick, A computer model for air-cooled refrigerant condensers with specified refrigerant circuiting, ASHRAE Trans. 87 (Part 1) (1981) 1106-1124.

[9] J.L. Threlkeld, Thermal Environmental Engineering, PrenticeHall Inc., New York, 1970.

[10] T.R. Bump, Average temperatures in simple heat exchangers, ASME J. Heat Transfer 85 (2) (1963) 182-183.

[11] R.J. Myers, The effect of dehumidification on the air-side heat transfer coefficient for a finned-tube coil, MS Thesis, University of Minnesota, Minneapolis, 1976.

[12] C.C. Wang, Y.C. Hsieh, Y.T. Lin, Performance of plate finned tube heat exchangers under dehumidifying conditions, ASME J. Heat Transfer 119 (1997) 109-117.

[13] Y.T. Lin, K.C. Hsu, Y.J. Chang, C.C. Wang, Performance of rectangular fin in wet conditions: visualization and wet fin efficiency, ASME J. Heat Transfer 123 (1991) 836-927.

[14] C.C. Wang, W.S. Lee, W.J. Sheu, J.S. Liaw, Empirical airside correlations of fin-and-tube heat exchangers under dehumidifying conditions, Int. J. Heat Exchangers 2 (2001) 151-178.

[15] S. Kandlikar, A general correlation for saturated two-phase flow boiling heat transfer inside horizontal and vertical tubes, ASME J. Heat Transfer 112 (1990) 219-228.

[16] ANSI/ASHRAE Standard 37, Methods of Testing for Rating Unitary Air-conditioning and Heat Pump Equipment, 1988.

[17] ASHRAE Standard 41-2, Standard Methods for Laboratory Airflow Measurement, 1987. 